\title{
Penggunaan kata Allah dan Yahweh dalam Kekristenan: Mengkritisi Teologi Yahweisme
}

Eben Munthe ${ }^{1}$, Munatar Kause ${ }^{2}$, Nicolien Meggy Sumakul ${ }^{3}$

${ }^{1}$ Sekolah Tinggi Teologi SEAPIN, Majalengka, Jawa Barat

${ }^{2}$ Sekolah Tinggi Agama Kristen Teruna Bhakti, Yogyakarta

${ }^{3}$ Sekolah Tinggi Teologi Rahmat Emmanuel, Jakarta

1ebenmunthe44@gmail.com, 2munatarmoses@gmail.com, ${ }^{3}$ meggysumakul@gmail.com

\begin{abstract}
The Bible is a Christian holy book and is believed to be the word of God, even though there is a lot of technical controversy with its terminology. The Bible is written in two major languages, Hebrew and Greek, besides some parts in Aramaic. In the process of becoming an Indonesian-language holy book, there are controversies that invite a lot of disputes, even some of the most correct claims. This includes the use of the word "Allah", which some groups consider inappropriate, because it is not the true identity of the Creator. The use of the word God to show the Creator is considered a fatal act, including the identity of other gods, so the use of YHWH or Yahweh is what the Bible should use. This article is a qualitative review of the literature using descriptive methods. In conclusion, the use of the word God in the Bible is not wrong, because it is a legacy from the apostles in the New Testament.
\end{abstract}

Keywords: Allah; Bible; Elohim; name of God; Yahweh; YHWH

\begin{abstract}
Abstrak: Alkitab merupakan kitab suci orang Kristen dan diimani sebagai firman Allah, sekalipun ada banyak kontroversi secara teknis dengan pengistilahan. Alkitab ditulis dalam dua bahasa besar, Ibrani dan Yunani, selain beberapa bagian menggunakan bahasa Aram. Dalam prosesnya menjadi kitab suci berbahasa Indonesia ada hal-hal kontroversi yang memunculkan banyak perselisihan, bahkan tidak sedikit klaim yang paling benar. Termasuk di dalamnya pengunaan kata "Allah", yang oleh sebagian kelompok dianggap tidak pantas, karena bukan identitas Sang Pencipta yang sejati. Penggunaan kata Allah untuk menunjukkan Sang Pencipta dianggap tindakan yang fatal, memasukkan identitas allah lain, sehingga penggunaan YHWH atau Yahweh itulah yang seharusnya digunakan Alkitab. Artikel ini merupakan kajian kualitatif literatur yang menggunakan metode deskriptif. Kesimpulannya, penggunaan kata Allah dalam Alkitab bukanlah sesuatu yang salah, karena itu merupakan warisan dari para rasul di Perjanjian Baru.
\end{abstract}

Kata kunci: Allah; Alkitab; Elohim; nama Allah; Yahweh; YHWH

\section{PENDAHULUAN}

Persoalan atau isu mengenai pengagung nama Yahweh bukanlah sebuah fenomena baru, karena telah muncul di sekitar awal tahun 2000-an. Fenomena tersebut sempat mendatangkan persoalan yang besar dari sekadar perpecahan di dalam tubuh gereja. Persoalan yang muncul adalah berupa reaksi dari kalangan muslim yang melayangkan surat edaran berupa teguran untuk tidak menggunakan nama "Allah" dalam segala sesuatu yang merepresentasikan kekristenan. Seperti yang diungkapkan dalam sebuah situs internet. 
Pada tahun 2004 sejalan dengan semangat Gerakan Nama Suci keluar surat teguran yang dikeluarkan Majlis Ta'lim Al-Rodd, Wonosobo disusul Badan Pengurus Pusat Ikatan Mubaligh Seluruh Indonesia. Teguran yang dikeluarkannya 'Majlis Ta'lim Al-Rodd' (Wonosobo, 28 Mei 2004) ditujukan kepada Pimpinan Lembaga Alkitab Indonesia, dan yang kedua dikirim oleh 'Badan Pengurus Pusat Ikatan Mubaligh Seluruh Indonesia' (Jakarta, 1 Nopember 2004) yang ditujukan Dirjen Bimas Kristen Protestan Depag RI dan Lembaga Alkitab Indonesia, dengan tembusan kebanyak pihak pemerintah. ${ }^{1}$

Dengan munculnya pemahaman baru yang berseberangan dengan konsep-konsep tradisional, maka akan selalu menghasilkan pro dan kontra yang tidak sedikit berujung kepada perselisi-han dan perpecahan gereja.

Hal yang lebih ekstrim terjadi di Malaysia, ketika sebuah tabloid Katolik Herald memenangkan gugatan tentang larangan penggunaan kata "Allah" bagi non-Muslim di Pengadilan Tinggi Malaysia. ${ }^{2}$ Peristiwa yang berbuntut pada pembakaran beberapa gereja di negara jiran itu diduga sebagai sebuah tindakan provokatif para pengikut aliran pengagung nama YAHWEH. Gerakan anti penggunaan nama Allah sebagai sesembahan orang Kristen terus diupayakan dengan tujuan agar Alkitab, khususnya Lembaga Alkitab Indonesia (LAI) pada akhirnya dapat menggantikan penggunaan nama Allah di dalam Alkitab, dan menggantikannya dengan nama YAHWEH. Golongan ini menganggap nama YAHWEH merupakan nama yang benar dibandingkan nama "Allah" di dalam Alkitab. Meskipun mendapatkan penolakan dari aras utama Kristen, baik Protestan maupun Katolik, namun kelompok ini terus memancangkan pengaruhnya hingga sedikit demi sedikit membuahkan hasil. Bentuk yang paling nyata adalah dengan mencetak Alkitab bagi kelompok mereka sendiri, yang sudah barang tentu bukan dikerjakan oleh LAI. Seperti yang diungkapkan dalam situs http://misiglobalsabda.blogspot.com:

Pada tahun 2002, kelompok Pengagung Nama Yahweh menerbitkan Kitab Suci Umat Perjanjian Tuhan, yang sama dengan KS-2000 menjadikan TB-LAI sebagai dasar dan mengganti nama 'TUHAN' dengan YAHWEH, dan 'Allah' dengan Tuhan. Soal penerbitan diakui diilhami The Scriptures (Afrika Selatan) dan mengikuti terjemahan nama Yahweh sesuai The Word of Yahweh yang diterbitkan oleh The Assembly of Yahweh, gerakan pelopor pemuja nama Yahweh di Amerika Serikat. ${ }^{3}$

Dengan hadirnya kitab khusus bagi gerakan pengagung Yahweh, maka di Indonesia kelom-pok ini telah menunjukkan kekuatan dan pengaruhnya. Dalam Prakata Kitab Suci Umat Perjanjian Tuhan yang mereka buat tersebut, mereka menyalahkan Yudaisme orthodok, karena telah mengganti nama YHWH dengan kata Adonai. Demikian juga dengan Septuaginta, karena menerjemahkan nama 'Yahweh' ke bahasa Yunani: Kurios, serta apa yang dilakukan Perjanjian Baru Yunani, yang mengikuti jejak Septuaginta.

Kehadiran kelompok ini telah membuat sebagian gereja Tuhan tidak lagi mengimani pewahyuan Alkitab secara utuh dan sempurna, sebagai yang datangnya dari Allah melalui inspirasi kepada para penulis Alkitab, terutama Perjanjian Baru. Kehadiran kelompok yang

\footnotetext{
${ }^{1}$ http://misiglobalsabda.blogspot.com/2011/08/v-behaviorurldefaultvml-o.html

${ }^{2}$ Jawa Pos, Senin, 25 Januari 2010

${ }^{3}$ http://misiglobalsabda.blogspot.com
} 
menyatakan dengan tegas tentang penggunaan nama Allah dalam Alkitab sebagai sebuah bentuk yang keliru (haram) dan mendukakan hingga menghujat YAHWEH tersebut telah berhasil mengakibatkan perpecahan di dalam tubuh gereja. Dampak kehadiran kelompok sangat meresahkan karena berusaha membatalkan kepercayaan iman Kristen, termasuk semangat reformasi dengan slogan sola scriptura-nya, terhadap otoritas dan wibawa Alkitab yang selama ini telah dipegang. Pengaruh itu juga telah menghasilkan beberapa aliran gereja telah keluar dari denominasi atau aras yang semula. Kehadiran kelompok ini ada di sekitar kita dan umat yang kita layani. Itu sebabnya, melalui seminar ini diharapkan dapat memberikan dasar teologi Kristen yang kuat dan sehat bagi seluruh elemen gereja Tuhan, agar dapat merespon kehadiran kelompok tersebut dan pengaruhnya yang meresahkan.

\section{METODE}

Penelitian ini merupakan sebuah kajian literatur dengan pendekatan kualitatif terhadap isu penggunaan nama ilahi dalam Alkitab. Metode yang digunakan adalah deskriptif analisis, di mana teks-teks Alkitab yang menunjukkan penggunaan nama-nama ilahi tersebut digunakan sebagai data untuk menunjukkan penggunaan nama-nama ilahi. Penggunaan literatur terkait digunakan untuk memberikan deskripsi kelomok Yahweisme ini dan ajarannya terkait nama-nama ilahi. Selanjutnya data rujukan biblikal dan literatur digunakan untuk menganalisis ajaran kelompok Yahweisme terkait nama-nama ilahi.

Secara singkat, sejarah kelompok ini dimulai dari sebuah gerakan yang menekankan kesucian Nama Allah, dengan istilah The Sacred Name Movement, yang diprakarsai oleh Penatua Clarence O. Dodd, seorang hamba Tuhan dari Church of God, Seventh Day, sekitar tahun 1930-an. Pada tahun 1980, penatua Don Mansager dengan beberapa penatua yang lain membentuk Yahweh's Assembly in Messiah (YAIM) at Rocheport, Missouri, USA. Pada tahun 1988 nama kelompok ini menjadi Yahweh's New Covenant Assembly (YNCA). Kemudian pada awal tahun 2007, muncul nama baru lagi Yahweh's Assembly in Yahshua (YAIY) yang dibentuk oleh Penatua Donald Mansager, Eugene Rodgers dan Roger. Namun kelompok ini hadir di Indonesia sekitar awal tahun 2000-an.

\section{Teologi Yahwehisne}

Secara prinsip, kelompok Pengagung Nama Yahweh (selanjutnya disebut Yahweisme) menentang penggunaan nama atau kata "Allah" dalam Alkitab sebagai sesembahan orang Kristen, dengan merujuk, setidaknya, pada tiga alasan: Pertama, "Allah" adalah dewa/berhala yang disembah orang Arab (pra-Islam) sebagai dewa air, dewa bulan (Hubal); Kedua, nama "Allah" berasal dari Babilonia yang menyembah berhala, lalu menyebar ke Arab; Ketiga, "Allah" adalah nama (diri) sesembahannya umat Islam, bukan Kristen. Selain itu juga, adanya penggunaan istilah TUHAN yang diterjemahkan dari bahasa Ibrani: יהוה (YHWH) yang dianggap seabagai kesalahan besar yang dapat mengarah pada tindakan menghujat nama Tuhan. Atas dasar inilah para Yahwe-isme bergiat untuk mengembalikan nama orisinil sesembahan orang Kristen yang alkitabiah, yaitu: יהוה (YHWH) dalam Alkitab. Alasan utamanya adalah, karena nama יהוה (YHWH) merupakan nama diri bukan kata turunan (generic name), seperti halnya dengan nama 
"Allah", yang merupakan nama diri sesembahan orang Islam atau agama orang-orang Arab pra-Islam.

\section{Penggunaan Nama-Nama Ilahi dalam Alkitab}

Untuk merespon ajaran (teologi) Yahweisme yang cukup meresahkan, maka penting untuk melihat penggunaan istilah Allah atau Tuhan dalam Alkitab, khususnya Perjanjian Lama.

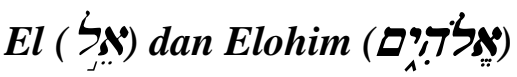

Nama 'El' dan variasinya (Elohim dan Eloah) adalah nama pertama yang digunakan dalam Alkitab sejak awal kitab Kejadian, baik sebagai nama pribadi maupun sebagai nama generic (sebutan), dan kemudian digunakan bangsa-bangsa keturunan Adam. Allah memperkenalkan diri pertama kepada Abraham dengan menggunakan variasi nama ini: (El Shadday; Allah Mahakuasa), dan kepada Yakub disebutkan "Akulah Allah

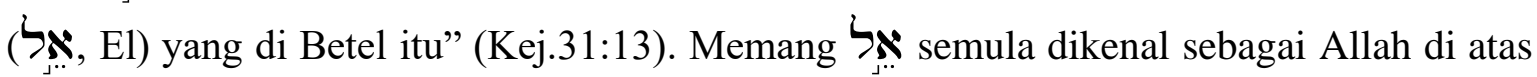
allah atau Allah Maha Tinggi, dan kemudian dipakai untuk menyebut Allah Israel. Nama El tidak sekedar menyebut kata generik sebagai "Allah tertinggi" tetapi dengan gabungan

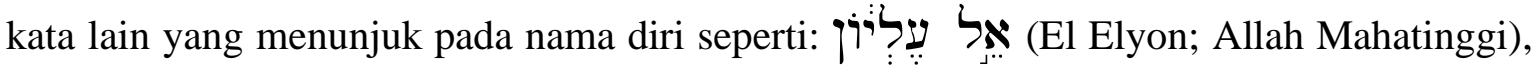

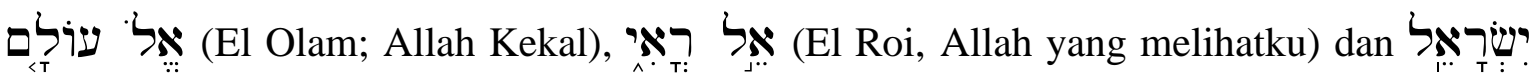

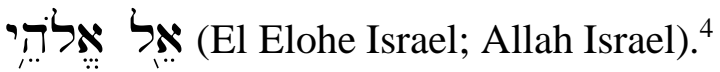

Sementara itu, nama Elohim banyak terdapat dalam Perjanjian Lama dalam pengertian sama dengan El dalam bentuk jamak (Kej. 1:26). Walaupun demikian kata Elohim selalu dipadukan dengan kata kerja bentuk tunggal, yang menunjukkan bahwa Elohim Israel tidak dipahami sama dengan bangsa-bangsa sekitarnya yang politeis. Nama Elohim menekankan bahwa Allah Pencipta adalah Tuhan yang mutlak atas ciptaan, seperti

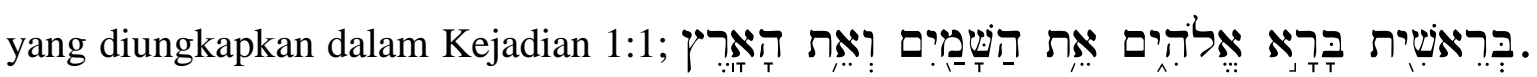
Elohim juga dipakai untuk mendeskripsikan berhala (Maz 135:5). Nama Elohim juga digunakan untuk menyatakan TUHAN Yahweh Israel. Nama Ketika Elia berkonfrontasi

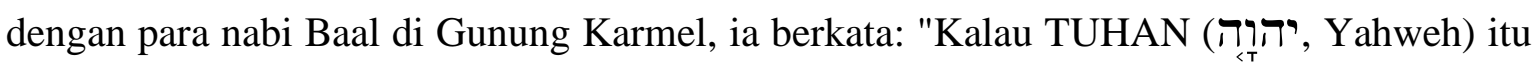
Allah (אַלדהים; Elohim), ikutlah Dia, dan kalau Baal, ikutlah Dia." (1Raj.18: 21,37,39). Elohim juga disejajarkan dengan El dan Yahweh dalam: "Aku, TUHAN (Yahweh), Allahmu (Elohim), adalah Allah (El) yang cemburu ..." (Ul.5:9).

\section{YHWH (}

Nama Yahweh sering disebut juga dengan istilah tetragrammaton, yang berarti empat abjad. Dalam Alkitab Bahasa Indonesia diterjemahkan sebagai "TUHAN" (semua huruf besar). Dalam tradisi naskah Pentateukh yang tertua, nama ini baru dikenal Musa sebagai TUHAN Allah yang membawa umat Israel keluar dari Mesir: "Akulah TUHAN (YHWH), Allah (Elohim) mu, yang membawa engkau keluar dari tanah Mesir, dari tempat perbudakan." (Kel.20:2). "Akulah TUHAN (YHWH), Aku telah menampakkan diri kepada Abraham, Ishak dan Yakub sebagai Allah (Elohim) yang Mahakuasa, tetapi dengan

${ }^{4}$ J.B. Payne, The Theology of the Older Testament (Michigan: Baker, 1978), 36 
namaKu TUHAN (YHWH) Aku belum menyatakan diri." (Kel.6:1-2, bdk. Kej.17:1; 28:3; $35: 11 ; 43: 14 ; 48: 3 ; 49: 25)$.

Umumnya teolog mempercayai bahwa Musa tidak berkenalan dengan TUHAN Allah yang berbeda dengan yang dikenal leluhurnya, dan dari Musalah pengajaran tentang TUHAN Allah (Yahweh) dalam terang Keluaran itu menjadi jelas. Baru setelah nama itu jelas (Kel.6:1-2) nama "Yahweh" digunakan retroaktif (diberlakukan mundur) untuk menyebut nama Allah (Elohim) Abraham, Ishak dan Yakub, nenek moyang Musa. Lagi firmanNya: "Beginilah kaukatakan kepada orang Israel: TUHAN (Yahweh), Allah (Elohim) nenek moyangmu, Allah (Elohim) Abraham, Allah (Elohim) Ishak, Allah (Elohim) Yakub, telah mengutus aku kepadamu: itulah nama-Ku untuk selama-lamanya dan itulah sebutanKu turun temurun." (Kel. 3:13-15).

Dalam penulisan Musa tentang masa awal sejarah dunia, nama diri Yahweh digunakan juga sebagai nama Tuhan pada zaman Enos: "Lahirlah seorang anak laki-laki bagi Set juga dan anak itu dinamai Enos. Waktu itulah orang mulai memanggil nama TUHAN (Yahweh)" (Kej. 4:26). Untuk menjadikan Yahweh bukan hanya sebagai El/ Elohim yang eksklusif milik bangsa Israel, maka nama diri Yahweh kemudian digunakan untuk mengganti nama diri El/Elohim agar Yahweh juga menjadi Allah umat manusia. Bahkan kemudian nama Yahweh disebut lebih dini lagi sebagai Allah pencipta langit dan bumi. "Demikianlah riwayat langit dan bumi pada waktu diciptakan. Ketika TUHAN (Yahweh) Allah (Elohim) menjadikan bumi dan langit” (Kej.2:4).

\section{Adonai (}

Dalam Bahasa Indonesia nama Adonai diterjemahkan sebagai "Tuan" atau "Tuhan”, yang sebenarnya merupakan nama panggilan untuk menghormati seseorang (1 Sam. 24:9; 26:17; Yer.22:18). Nama ini kadang-kadang dipadukan bersama-sama untuk menjelaskan nama Yahweh sebagai “TUHAN (YHWH), Tuhan (Adonai)...” (Yos.3:13; Maz. 97:5). Adonai juga biasa digunakan pengganti sebagai pengganti ucapan untuk nama $Y H W H$, demi menghindari pengucapan secara sembarangan, atau yang disebut juga qere perpetuum. ${ }^{5}$ Dalam Alkitab Perjanjian Lama ada sekitar 300 kali Adonai dikaitkan sebagai kata di depan kata YHWH (Adonai Yahweh). Dalam menerjemahkan nama Adonai YHWH untuk tidak menimbulkan pengulangan maka tidak diterjemahkan sebagai "Tuhan TUHAN" melainkan sebagai "Tuhan ALLAH." Di sini YHWH diterjemahkan sebagai "ALLAH" (semua huruf besar), bukan "Allah" (huruf kecil dengan huruf pertama kapital) yang biasanya adalah terjemahan dari el/elohim/eloah. Adakalanya Adonai juga digunakan sebagai pengganti nama $Y H W H$ (Yes. 6:1,8; Mi 4:13; Zak 4:14; 6:5). Baik El, Elohim maupun Eloah dapat menjadi nama diri maupun sebagai gelar, sebutan atau panggilan umum yang disembah. ${ }^{6}$

Pengertian nama El, Elohim maupun Eloah tidaklah statis tetapi berkembang, dan demikian juga dalam hubungan dengan nama diri " $Y H W H$ ". Perkembangan juga terjadi dimana penggunaan nama El, Elohim dan Eloah itu berkembang dalam suku-suku bangsa

${ }^{5}$ J. Weingreen, A Practical Grammar for Classical Hebrew (London: Oxford Press, 1978), 23

${ }^{6} \mathrm{G}$. Johanes Botterwech, et.al. (eds), Theological Dictionary of the Old Testament, I: 253-261. 
keturunan Sem lainnya. Awalnya nama "El" di rumpun Semit-Timur dan Akkadian kuno adalah "il, ilu, ilum" dan di Amorit dan Arab-Utara berkembang menjadi "ila/ilah." Nama Yahweh juga turut dipakai secara bergantian bersamaan dengan penerjemahan "El" ketika kedua nama itu diangggap identik dalam konteks tertentu. Nama "elohim" (Ibrani) sama asal katanya dengan "elah" (Aram) dan "ilah" (Arab). ${ }^{8}$ Di kayu salib ketika Yesus berseru "AllahKu" Ia berbicara dalam Bahasa Aram, maka "elah" juga berkembang menjadi "eli" (Mat.27:46) atau "eloi" (Mar.15:34) pada masa Yesus hidup. Sekiranya Ia berseru dalam bahasa Ibrani "elohim" diberi akhiran kata ganti milik menjadi "Elohay." Hal ini menunjukkan bahwa Yesus tidak memakai bahasa Ibrani, tetapi bahasa Aram, sangat berbeda dengan klaim Pengagung Nama Yahweh.

\section{PEMBAHASAN}

Kelompok Pengagung Nama Yahweh menggunakan beberapa referensi ayat Alkitab untuk menunjuk pada nama pribadi: "Inilah Namaku untuk selama-lamanya" (Kel.3:15); "Aku ini $Y H W H$, itulah nama-Ku" (Yes.42:8); dan "NamaKu YHWH " (Yer.16:21). Perlu diperhatikan, bahwa sebelum masa Musa hanya nama El yang dikenal, dan baru pada masa Musa nama YHW YHWH H diperkenalkan (Kel.6:1-2). Tuhan yang menyatakan diri pada Adam dengan nama "El/Elohim," Adam dan generasi awal memahami nama itu sebagai pribadi tunggal. Tetapi kemudian pengertian "el" itu merosot pada pengertian politeistik (elohim). Dalam perkembangan penyembahan kemudian "el” dianggap sebagai "pencipta/penguasa" atau yang tertinggi dari pantheon deretan sesembahan. ${ }^{9}$ Dari sini mulailah dipakai nama diri "El”" yang definitif (The God).

Sekalipun nama Yahweh sudah diperkenalkan kepada Musa (Kel 6:2-3), nama El juga masih tetap digunakan dalam Perjanjian Lama sesudah Musa. Dalam Mazmur 43-83 lima belas kali "El" disebut sebagai nama diri Yahweh, dan khusus dalam Mazmur 78 enam kali. Penggunaan "El" sebagai nama diri dan gelar umum bersama-sama lebih banyak terjadi pada saat awal sejarah Israel. Tahun-tahun menjelang pembangunan Bait Allah pertama, "Yahweh" semakin dominan menggantikan "El" sebagai nama diri dan "elohim" menggantikan "el” sebagai nama sebutan/panggilan/gelar. Dengan meningkatnya praktIk menghindari penyebutan nama Yahweh untuk menjaga kesucian nama itu selama dan sesudah pembuangan, penggunaan "El" sebagai nama diri meningkat kembali. ${ }^{10}$ Luasnya tumpang tindih dalam sifat, julukan antara nama Yahweh dengan El memberi kesan bahwa Yahweh yang walau disebut dengan nama El, Ia berbeda dari konsep allah yang ada dalam konteks lama penggunaan nama yang awalnya bersifat politeistik. ${ }^{11}$

Ketika Perjanjian Lama diterjemahkan ke dalam bahasa Yunani di mana Yahweh diterjemahkan menjadi Kurios dan El/Elohim/Eloah diterjemahkan menjadi theos, tidak ada petunjuk sedikit pun dalam Perjanjian Lama maupun Perjanjian Baru yang menunjukkan bahwa Yahweh merasa terhujat atas penerjemahan namaNya itu. Yesus

\footnotetext{
${ }^{7}$ Ibid., 242-244

${ }^{8}$ J.D. Douglas, gen. ed., New Bible Dictionary (Illinois: Intervarsity Press, 1996), 420

${ }^{9}$ Herlianto, Siapakah yang Bernama Allah Itu? (Jakarta: BPK Gunung Mulia), 24

${ }^{10}$ Botterwech, op.cit., 258-259

${ }^{11}$ Ibid., 260
} 
membaca Lukas 4:18-19 dari Septuaginta yang sudah menerjemahkan nama Yahweh menjadi "Kurios." Di hari Pentakosta Roh Kudus sendiri mengilhami para Rasul sehingga mereka dapat berbicara dan memuliakan Tuhan dalam bahasa-bahasa pendengar, nama $Y H W H$ dan Elohim diucapkan dalam terjemahan berbagai bahasa pendengar juga. Maka, kalau Allah Bapa, Yesus Kristus dan Roh Kudus sendiri merestui penerjemahan nama mereka, jelaslah bahwa yang dikehendaki Allah bukan pengucapan huruf-huruf nama itu secara literal, tetapi kemuliaan dari Pribadi Tuhan yang tersirat dalam nama itu.

\section{Makna Teologis dari Nama}

Dalam Alkitab, khususnya Perjanjian Lama, nama tidak diberikan hanya supaya setiap orang memiliki identitas individual yang membedakan panggilannya dengan orang lain. Pemberian nama, baik oleh Tuhan maupun oleh manusia selalu melibatkan berbagai aspek yang dinamis, baik di masa lampau, kini maupun ke masa mendatang. Bambang Noorsena, pendiri Institute for Syriac Christian Studies, menjelaskan setidaknya tiga makna dari nama Yahweh, yaitu: (1) menunjuk kepada Pribadi itu sendiri; (2) pribadi yang diungkapkan; (3) pribadiyang hadir secara aktif." 12

Dalam Imamat 24:11 "Anak perempuan Israel itu menghujat Nama TUHAN dengan mengutuk..." Dalam teks bahasa asli kata "TUHAN" secara literal tidak terdapat, tetapi hanya dicantumkan kata אִת (hashem: Nama itu, Sang Nama). Di sini nama menunjuk kepada Pribadi yang di-Nama-kan. Karena itu, yang dipentingkan bukan penyebutan Nama Ilahi YHWH dalam bahasa asli Ibrani, melainkan lebih menunjuk kepada Pribadi

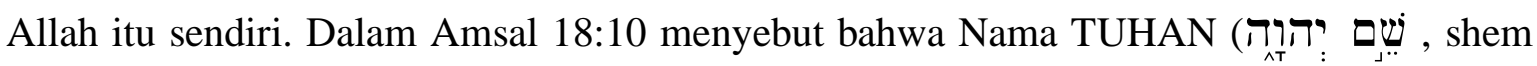
Yahweh) adalah menara yang kuat. Nama TUHAN yang dimaksud di sini adalah Pribadi Allah yang hidup dengan kekuasaan ilahi-Nya, yang menjaga dan melindungi umat-Nya. "Nama" di sini menunjuk kepada apa yang diketahui tentang Pribadi-Nya.

Yesaya 30:27 mengatakan: "Perhatikanlah, TUHAN datang dari tempat-Nya yang

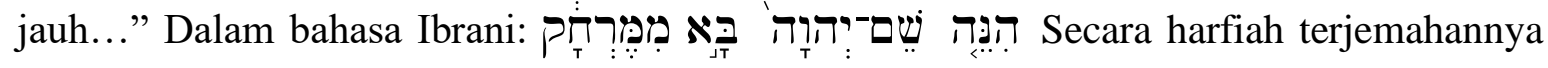
seharusnya “...Nama TUHAN datang..." Di sini nama menekankan "pengungkapan Pribadi-Nya, sehingga itu LAI tidak harus menyisipkan "Nama", karena menyatakan Diri Tuhan bukan sekedar nama harfiah. Di Gunung Karmel nabi Elia mengusulkan "peperangan Nama" antara Yahweh dengan nama ilah-ilah lain. Dalam persistiwa ini "Nama" menunjuk kepada Pribadi yang hadir, yang dibuktikan dengan menjawab doa orang yang menyerukan Nama-Nya. "Kemudian biarlah kamu memanggil nama ilahmu (באליהילֶם (בְּשִׁם

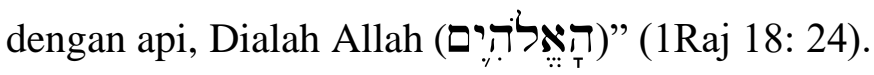

\section{Penggunaan Nama Yahweh}

Ada yang unik ketika Musa menanyakan Nama Tuhan untuk pertama kali, "Bagaimana

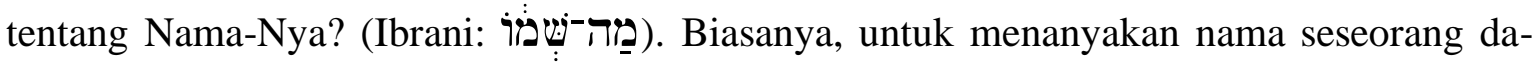

\footnotetext{
${ }^{12}$ www.iscs.or.id>article> Nama Yahweh: Harus Dipertahankan atau Boleh Diterjemahkan Dalam Bahasa Lain.html
} 
lam bahasa Ibrani memakai kata ganti (siapakah), tetapi dalam ayat ini menggunakan

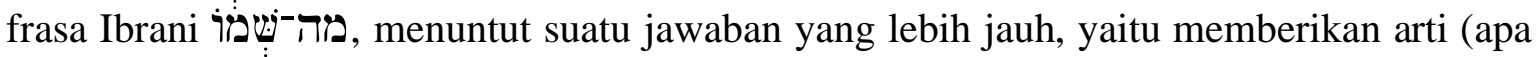
dan bagaimana) atau hakikat dari nama itu. Bukan sekedar menyebutkan nama, melainkan lebih pada makna yang menunjuk kuasa di balik Dia yang di-Nama-kan.

Secara gramatikal, apabila Allah sendiri yang mengucapkan Nama-Nya, maka akan dijumpai bentuk אהיו: (Aku Ada). Sedangkan bila umat Allah yang mengucapkan tentu saja memakai kata ganti orang ketiga Yahweh (akar katanya $\underset{T \mathrm{~T}}{\boldsymbol{4}}$; Dia ada). Keberadaan Allah apabila dikaitkan dengan ketiga aspek waktu tersebut, dalam bahasa Ibrani adalah:

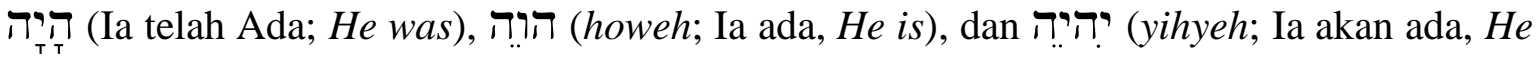
will be). Maksudnya di sini, Allah itu Mahakekal, tidak terikat oleh aspek waktu, dan hal itu dibuktikan dengan kekuasaan-Nya yang selalu dinamis. Artinya, bahwa Alkitab lebih mengacu kepada makna teologis di balik Nama itu, yaitu kuasa-Nya yang hidup, dan bukan mempertahankan secara harfiah huruf-huruf mati tersebut (tetragrammaton).

\section{Pemakaian Nama Yahweh di Luar Alkitab}

Berdasarkan inskripsi-inskripsi kuno yang ditemukan di Kuntilet Ajrud, nama Yahweh pernah dipuja bersama-sama dewi kesuburan Asyera. Salah satu bunyi inksripsi Kuntilet Ajrud dalam bahasa Ibrani: "Birkatekem le-Yahweh syomron we le 'asyeratah" (Aku memberkati engkau demi Yahwe dari Samaria dan demi Asyera). ${ }^{13}$ Yahweh pernah dipuja secara salah di sekitar wilayah Samaria, terbukti dari inskripsi Kuntilet Ajrud dan Khirbet el-Qom, namun hal itu tidaklah membuat umat Tuhan di Perjanjian Lama lantas berhenti menyembah Nama itu, hanya karena ada pihak yang menggunakan nama itu dalam praktek politeisme. Demikian juga halnya dengan istilah "Allah" yang telah disalahgunakan di sekitar Mekkah sebelum zaman Islam. Tetapi nama Allah itu tetap dipakai sebagai sebutan bagi Khaliq langit dan bumi oleh orang-orang Kristen Arab di wilayah Syria. ${ }^{14}$ Hal ini juga dibuktikan dari sejumlah inskripsi Arab pra-Islam lainnya yang semuanya ternyata berasal dari lingkungan Kristen.

Salah satu inskripsi kuno yang lain ditemukan pada tahun 1881 di kota Zabad, sebelah tenggara kota Allepo (Arab: Halab), yang meneguhkan dalil tersebut. Inskripsi Zabad ini telah dibuktikan tanggalnya berasal dari zaman sebelum Islam, tepatnya tahun 512. Inskripsi ini diawali dengan perkataan Bism-al-lah, "Dengan Nama Allah", dan kemudian diusul dengan nama-nama orang Kristen Syria. Bunyi lengkap inskripsi Arab Kristen ini dapat direkonstruksi sebagai berikut: "Bism' al-lah: Serjius bar 'Amad, Manaf wa Hani bar Mar al-Qais, Serjius bar Sa'd wa Sitr wa Sahuraih" (Dengan Nama Allah: Sergius putra Amad, Manaf dan Hani putra Mat al-Qais, Sergius putra Sa'ad, Sitr dan Shauraih.) ${ }^{15}$ Kata Al-lah (Allah) sudah dipakai oleh orang Krsiten dalam makna tauhid Kristen, dan bukan dalam makna dewa berhala. Maka jelaslah, bahwa orang Kristen di

\footnotetext{
${ }^{13}$ Andrew D. Clarke dan Bruce W. Winters (eds.), Satu Allah Satu Tuhan: Tinjauan Alkitabiah tentang Pluralisme Agama (Jakarta: BPK Gunung Mulia, 1995), 50

${ }^{14}$ Bambang Noorsena, Menuju Dialog Teologis Kristen-Islam (Yogjakarta: Andi Offset, 2001), 70

${ }^{15}$ Bacaan Bism al-lah (Dengan Nama Allah) berasal dari Yasin Hamid al-Safadi, Kaligrafi Islam.dit. oleh Abdul Hadi WM (Jakarta: PT. Panca Simpati, 1986), 6
} 
lingkungan Arab zaman pra-Islam telah mengenal dan menggunakan nama Allah, dan mereka tidak memiliki kekuatiran bahwa penggunaan nama Allah itu akan membuat iman mereka menjadi rancu dengan agama masyarakat Arab jahiliyah.

\section{Penggunaan Bahasa Ibrani, Yunani dan Arami Pada Masa Perjanjian Baru}

Cukup mengherankan jika "para penggugat nama Allah" itu selalu menggunakan $\mathrm{Ha} \mathrm{Berit}$ ha-Hadasah (Perjanjian Baru Bahasa Ibrani) dan memperlakukannya seolah-olah itulah teks bahasa aslinya. Dalam Perjanjian Baru berbahasa Ibrani ini tentu saja akan dijumpai nama (kata) Yahweh. Tetapi Perjanjian Baru berbahasa Ibrani itu adalah hasil terjemahan dari bahasa Yunani, oleh United Bible Society in Israel yang proyeknya dimulai pada tahun 1970-an. Perjanjian Baru aslinya ditulis dalam bahasa Yunani Koine dan para rasul Yesus tidak mempertahankan nama diri Yahweh. Harus dipertimbangkan bahwa Yesus ketika masuk ke sinagoge, Ia mengutip teks-teks Perjanjian Lama dalam bahasa Ibrani (Lukas 4:18-19). Namun, kita juga harus paham bahwa Ia juga telah bercakap-cakap dalam bahasa Aram dengan murid-murid-Nya sebagai bahasa daerah masyarakat Yahudi pada zaman itu.

Para Rasul menulis Perjanjian Baru dalam Bahasa Yunani karena bahasa ini menjadi bahasa yang paling luas digunakan di seluruh wilayah kekaisaran Romawi pada zaman itu. Meskipun demikian, Perjanjian Baru Yunani itu tidak dapat dipahami tanpa melihat latar belakang budaya Arami. ${ }^{16}$ Oleh karena kitab ini masih memelihara beberapa ungkapan Arami - yang waktu itu juga biasa disebut Ibrani - sebab dianggap sebagai salah satu dialek tutur saja bagi masyrakat Yahudi di Galilea. Beberapa contoh kata Arami yang dipelihara itu, antara lain: Talita Kum (Mrk. 5:41), Gabbata (Yoh.19:13), dan kata: Maranatha (1 Kor. 16:23).

Salah satu bukti bahwa Yesus membaca Targum berbahasa Arami, di mana kata Alaha (yang cognate dengan bentuk Ibrani "Eloah" dan Arab "Allah") adalah ungkapan Yesus dalam Markus 15:33, "Elohi, Elohi, lamah shavaktani." Sebab dalam teks Mazmur

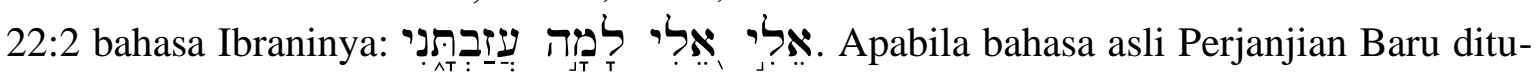
lis dalam Bahasa Yunani, maka para rasul tentu tidak mempertahankan nama Yahweh. Apa dasar dan alasan Pengagung Nama Yahweh mempertahankannya dengan demikian ekstrim? Para rasul penulis Perjanjian Baru menerjemahkan Kyrios (Tuhan) sebagai kata ganti Yahweh. Misalnya Ulangan 6:4 yang dalam bahasa asli Ibrani sering disebut

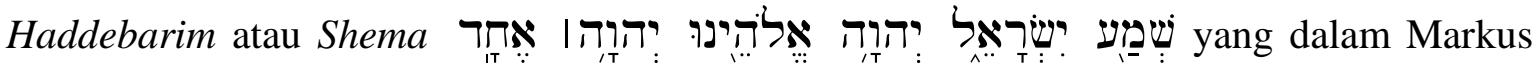

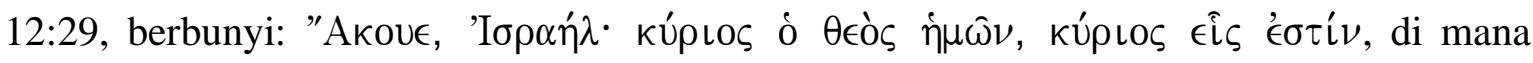
kata יהוז diterjemahkan kúpıos dalam bahasa Yunani. Jika demikian, apakah berarti para penulis PB salah dalam menuliskan nama Tuhan?

\section{Allah Sebagai Nama Diri dan Nama Generik}

Bagaimana dengan klaim yang menyebutkan bahwa nama "Allah" dalam bahasa Arab itu sebenarnya nama dewa atau tepatnya "Dewa Air/Pengairan"? Dari pembahasan mengenai nama diri dan nama generik El/ Elohim/Eloah terdahulu, kita telah melihat bahwa nama "Allah" dalam Bahasa Arab juga menunjuk pada nama El/Elohim/ Eloah yang sama. Bila kita melihat Bahasa Arab-Aram yang diucapkan Yesus di kayu salib "Eloi/Eli” yang

\footnotetext{
${ }^{16}$ Matthew Black, An Aramaic Approach to the Gospels and Acts (Oxford: At the Calrendon Press, 1967).
} 
berasal dari Arab-Asli, maka nama Allah yang merupakan kependekan "Al-Ilah" adalah juga berasal dari kata El/Elohim/Eloah yang sama. "Kata 'Allah' merupakan pengkhususan dari kata al-ilah (ketuhanan). Nama 'Allah' telah dikenal dan dipakai sebelum Al-Qur'an diturunkan."17 Memang kata "al-ilah" menunjukkan adanya artikel "al” yang definitif, dan sekalipun ada kata penunjuk definitif "ha" dalam Bahasa Ibrani kata penunjuk itu tidak selalu dipakai. Dalam pengertian El/Elohim/Eloah, kata itu bisa bersifat nama umum /generik tetapi juga nama diri yang definitif, dan dalam perkembangan Bahasa Arab kata penunjuk "al" itu ditekankan. Memang ada ayat Ibrani yang menyebut "Yahweh, hu haElohim" (1Raj.18:39) tetapi dalam banyak bagian kata penunjuk definitif itu tidak selalu digunakan.

Sejarah menunjukkan bahwa nama Allah sudah lama dipakai oleh orang Arab jauh sebelum masa Islam maupun masa Jahilliyah dimana nama "al-ilah" itu dimengerti sebagai "dewa air" oleh sebagian orang Arab. Dalam traktat berjudul "Siapakah yang Bernama Allah Itu" ditonjolkan kutipan Smith bahwa "ALLAH adalah nama dewa yang disembah penduduk Mekah." 18 Faktanya (yang dengan sengaja tidak dikutip Pengagung Nama Yahweh) Smith menyebut lebih dahulu bahwa dalam Al-Quran "nama Allah berasal dari kata Al-Ilah yang dipercayai oleh orang Arab sama dengan Allah Adam, Nuh, Sem dan Abraham dari Alkitab."19 Kutipan Al-Quran dari Tafsir Quran Karim berikut memperjelas hal itu:

Sesungguhnya Aku akan menjadikan seorang khalifah diatas bumi (Adam). Maka jawab mereka itu: Adakah patut Engkau jadikan di atas bumi orang yang akan berbuat bencana dan menumpahkan darah, sedang kami tasbih memuji Engkau dan menyucikan Engkau? Allah berfirman: Sesungguhnya Aku mengetahui apa yang tiada kamu ketahui. (Al-Baqarah 2:30).

Kami telah beriman kepada Allah dan (Kitab) yang diturunkan kepada kami dan apaapa yang diturunkan kepada Ibrahim, Isma'il, Ishaq, Ya'qub dan anak-anaknya, (begitu juga kepada kitab) yang diturunkan kepada Musa dan 'Isa, dan apa-apa yang diturunkan kepada nabi-nabi dari Tuhan mereka, tiadalah kami perbedakan seorang juga di antara mereka itu dan kami patuh kepada Allah (2:136).

Dari kutipan di atas kita melihat bahwa istilah "Allah" sudah lama digunakan dan menunjuk pada 'El/Elohim/Eloah' dalam Alkitab. Rupanya pengertian mengenai nama "Allah" itu kemudian merosot pada jaman Jahiliyyah menjelang kelahiran Islam pada abad VII sehingga oleh orang Arab-Mekah dipercaya sebagai "dewa air" atau dewa berhala lainnya. Sekalipun demikian, tradisi nama Allah yang asli tidak terhapus sama sekali karena masih ada kelompok keagamaan yang bernama "hunafa" yang masih berpegang kepada pengertian Allah yang semula. ${ }^{20}$

Gagasan tentang Tuhan Yang Esa yang disebut dengan Nama Allah, sudah dikenal oleh Bangsa Arab kuno ... Kelompok keagamaan lainnya sebelum Islam adalah hunafa' (tunggal: hanif), sebuah kata yang pada asalnya ditujukan pada keyakinan monotheisme zaman kuno yang berpangkal pada ajaran Ibrahim dan Ismail.

\footnotetext{
${ }^{17}$ Glasse, Op Cit, . 23

${ }^{18}$ Djohan Effendi, Op. Cit., 258. Dikutip dari Huston Smith, The Religions of Man, 1963, 204

${ }^{19}$ Smith, Op.Cit., 202

${ }^{20}$ Herlianto, Op.cit., 126
} 
Menjelang abad ke-7, kesadaran agama Ibrahim di kalangan bangsa Arab ini telah menghilang, dan kedudukannya digantikan oleh pemujaan sejumlah berhala ... dalam waktu 20 tahun seluruh tradisi Jahiliyyah tersebut terhapus oleh ajaran Tuhan yang terakhir, yakni Risalah Islam. ${ }^{21}$

Jadi makin jelas bahwa nama Allah semula merosot pada jaman jahilliyah menjelang kelahiran Islam sehingga penduduk sekitar Mekah mengenalnya sebagai "dewa air" atau nama berhala lainnya, tetapi jelas juga bahwa ada yang masih memahami dalam pengertian semula. Di samping itu, di sekitar Muhammad juga ada orang-orang Kristen dan Yahudi yang turut memberikan andil dalam pengenalan Muhammad akan monoteisme. Kelihatannya kelompok inilah yang memperkenalkan nama "Allah" pada pengertiannya yang asli dan menjadi inspirasi Muhammad sehingga dipulihkan dalam agama Islam.

Contoh kemerosotan pengertian akan nama yang sama ini bisa dilihat dalam sejarah Israel, yaitu penggunaan nama 'Elohim' juga sering merosot juga. Dalam Kel 32:4 kita dapat melihat bahwa 'allah Lembu Emas' yang disembah umat Israel saat Musa naik ke Gunung Sinai, dalam bahasa aslinya juga ditulis dengan kata "Elohim," padahal Tuhan dan Musa menyalahkan mereka dan agar mereka kembali kepada "Yahweh (TUHAN), Elohim (Allah) Israel" yang benar (Kel.32:26-27). Jadi dalam satu perikop, kata Elohim dipakai baik untuk Yahweh maupun berhala. Pembedaannya bergantung pada konteks kalimatnya.

Penggunaan nama yang sama dipakai untuk menyebut dua konsep berbeda tentang yang disembah. Dari sini kita melihat bahwa nama "Allah" sama halnya dengan "Elohim" bisa dalam pengertian semula, bisa juga merosot untuk menyebut misalnya 'Dewa Air' dalam jalur Ismael atau untuk menyebut 'Lembu Emas' dalam jalur Ishak. Untuk membedakan pengertiannya, dalam jalur Israel digunakan istilah yang diberi penjelasan yaitu "Allah Abraham, Ishak dan Yakub." Dengan penjelasan Allah yang terkait dengan Abraham, Ishak dan Yakub, maka jelas yang dimaksud bukanlah berhala yang ada di bangsa Arab zaman pra Islam, sebab para Bapa Leluhur itu tidak pernah berhubungan dengan bangsa Arab jahiliyah.

Pada hari Pentakosta, Roh Kudus memampukan para murid untuk berbicara dalam berbagai bahasa orang-orang yang hadir di Yerusalem (Kis. 2:4-11). Salah satu bahasa yang disebutkan hadir di sana adalah bahasa Arab. Walau tidak disebutkan secara eksplisit, namun dengan melihat tradisi Kristen Arab yang telah menggunakan kata "Allah," tidak diragukan lagi bahwa nama itu juga dipakai dalam bahasa yang didorong oleh Roh Kudus untuk menggunakannya. Perjanjian Baru ditulis dalam bahasa Yunani Koine mengikuti kosakata LXX dimana digunakan nama "Kurios" dan "Theos" juga. Perjanjian Baru kemudian diterjemahkan ke dalam bahasa Aram Siria (Peshitta, abad II-III) dimana Yahweh/Adonai/Kurios diterjemahkan menjadi Marya dan El/Elohim/Eloah diterjemahkan "Elah/Alah/Elaha/Alaha." Penerjemahan Alkitab seutuhnya berlanjut ke dalam bahasabahasa lain, seperti Latin, Inggris dan termasuk Arab.

Sejak kehadiran Islam penggunaan nama Allah oleh orang Yahudi, Kristen dan Arab di negara-negara berbahasa Arab selama 15 abad sampai kini tidak pernah menjadi masalah. Masalah seolah timbul belakangan ini ketika kelompok Pengagung Nama Yahweh me-

\footnotetext{
${ }^{21}$ Glasse, Op Cit, 50-51
} 
maksakan kehendak mereka menuntut semua nama TUHAN dalam Alkitab (terjemahan LAI) diganti Yahweh dan nama Allah dihapuskan, karena dianggap nama Dewa air/bulan. Yang memprihatinkan, kelompok Pengagung Nama Yahwehlah yang kemudian memprovokasi kalangan fundamentalis Islam agar mendukung langkah mereka untuk melarang umat Kristen menggunakan nama Allah. Hal itu antara lain terungkap dengan keluarnya Surat Mubaligh yang melarang umat Kristen menggunakan nama Allah, padahal umat Kristen sudah jauh lebih dahulu menggunakan nama itu. Anggapan bahwa istilah 'Tuhan' adalah sebutan dan 'Allah' itu nama diri Tuhannya Islam, adalah pembatasan sempit karena keterbatasan nalar para Pengagung Nama Yahweh sendiri. Mereka seharusnya bisa membuka diri dan keluar dari benteng-benteng pertahanannya untuk mengerti persoalannya dengan wawasan yang lebih luas.

Bahwa terjemahan LAI tidak bebas dari kesalahan dan direvisi merupakan hal yang dapat dimaklumi, karena pengertian bahasa itu berkembang, justru menyedihkan kalau Pengagung Nama Yahweh menjiplak apa yang dianggapnya "salah" dengan hanya mengganti nama-nama tertentu dalam Alkitab, lalu kemudian menganggap Kitab Suci jiplakan (Kitab Suci Torah dan Injil dan Kitab Suci Umat Perjanjian Tuhan) sebagai satu-satunya yang "benar". Di Malaysia memang pernah ada kelompok fundamentalis Islam melarang penggunaaan nama Allah, namun fakta sejarah menunjukkan bahwa pada 1976 di Malaysia diterbitkan Alkitab Bahasa Melayu lengkap (1987) oleh Lembaga Alkitab di Singapura, Malaysia dan Brunei. Kemudian terjemahan itu disempurnakan lagi, di samping versi lain Alkitab Berita Baik Bahasa Melayu yang diterbitkan. Semua Alkitab ini menggunakan kata Allah untuk menerjemahkan El/Elohim/Eloah dan Theos.

Bila Yesus sendiri menggunakan Bahasa Arab-Aram, maka adalah wajar kalau orang-orang Arab kuno yang menjadi Kristen kemudian menggunakan 'Allah' Bahasa Arab untuk menyebut nama 'El/Elohim' sebelum kehadiran Agama Islam. Daud H. Susilo, konsultan Lembaga Alkitab Sedunia, mengemukakan bahwa:

Jauh sebelum kehadiran Agama Islam, orang Arab yang beragama Kristen sudah menggunakan (baca: menyebut) 'Allah' ketika mereka berdoa kepada el, elohim, eloah. Bahkan tulisan-tulisan kristiani dalam Bahasa Arab pada masa itu sudah menggunakan allah sebagai padan kata untuk el, elohim, eloah. Sekarang ini, "Allah" tetap digunakan dalam Alkitab Bahasa Arab, baik terjemahan lama (Arabic Bible) maupun terjemahan yang baru (Today's Arabic Version). ${ }^{22}$

Hal ini diperjelas dari sumber Islam sendiri.

Gagasan tentang Tuhan Yang Esa yang disebut dengan Nama Allah, sudah dikenal oleh Bangsa Arab kuno. Ajaran Kristen dan Yudaisme dipraktikkan di seluruh jazirah ... Nama "Allah" telah dikenal dan dipakai sebelum al-Qur'an diwahyukan ... Kata itu tidak hanya khusus bagi Islam saja, melainkan ia juga merupakan nama yang, oleh umat Kristen yang berbahasa Arab dari gereja-gereja Timur, digunakan untuk memanggil Tuhan. ${ }^{23}$

Bahkan Nurcholish Majid, seorang cendekiawan Muslim dan mantan Rektor Universitas Paramadina, mengatakan bahwa dari dahulu sampai sekarang, di kalangan Bangsa Arab

\footnotetext{
${ }^{22}$ Daud Susilo, Forum Biblika, LAI, no.8/1998, 102.

${ }^{23}$ Glasse, Op. Cit, 5023
} 
terdapat kelompok-kelompok non-Islam, yaitu Yahudi dan Kristen dan mereka juga menyebut Allah. ${ }^{24}$

\section{KESIMPULAN}

Persoalan nama Pencipta atau Dia yang layak disembah dalam Alkitab, harus dipandang sebagai persoalan teologis-bibliogis yang memuat implikasi pada pengenalan pribadi yang melekat pada nama apa yang akan digunakan dan disebutkan. Allah tidak terikat pada nama apa pun yang disematkan terhadapNya, kecuali pada pribadiNya. Itu sebabnya, gerakan pengagung nama Yahweh merupakan sebuah fenomena yang kurang memahami implikasi dari penyataan Allah yang sejati lewat Alkitab.

\section{REFERENSI}

Black, Matthew. An Aramaic Approach to the Gospels and Acts, Oxford: At the Calrendon Press, 1967

Botterwech, G. Johanes et.al. (eds). Theological Dictionary of the Old Testament, I: 253261

Clarke, Andrew D. dan Bruce W. Winters (eds.), Satu Allah Satu Tuhan: Tinjauan Alkitabiah tentang Pluralisme Agama, Jakarta: BPK Gunung Mulia, 1995

Douglas, J.D. gen. ed., New Bible Dictionary, Illinois: Intervarsity Press, 1996 Herlianto, Siapakah yang Bernama Allah Itu? Jakarta: BPK Gunung Mulia http://misiglobalsabda.blogspot.com/2011/08/v-behaviorurldefaultvml-o.html http://misiglobalsabda.blogspot.com

Jawa Pos, Senin, 25 Januari 2010

Payne, J.B. The Theology of the Older Testament (Michigan: Baker, 1978), 36

Madjid, Nurcholis. Islam, Doktrin dan Peradaban, Jakarta: Paramadina, 1992.

Noorsena, Bambang. Menuju Dialog Teologis Kristen-Islam, Yogjakarta: Andi Offset, 2001

Siahaya, Karel Martinus. "Dampak Sosial Politik Terhadap Perkembangan Ekonomi Umat Allah Zaman Perjanjian Lama." Jurnal Teruna Bhakti 2, no. 1 (2019): 12-26.

Siahaya, Karel Martinus, Johannis Siahaya, and Nunuk Rinukti. "Tuhan Ada Di ManaMana: Mencari Makna Bagi Korban Bencana Di Indonesia." KURIOS (Jurnal Teologi dan Pendidikan Agama Kristen) 6, no. 1 (2019): 103-113Smith, Huston. The Religions of Man, 1963

Weingreen, J. A Practical Grammar for Classical Hebrew, London: Oxford University Press, 1978.

www.iscs.or.id>article> Nama Yahweh: Harus Dipertahankan atau Boleh Diterjemahkan Dalam Bahasa Lain.html

Yasin Hamid al-Safadi, Kaligrafi Islam, dit. oleh Abdul Hadi WM, Jakarta: PT. Panca Simpati, 1986.

\footnotetext{
${ }^{24}$ Nurcholis Madjid, Islam, Doktrin dan Peradaban (Jakarta: Paramadina, 1992), XCV
} 